\title{
Intravenous immunoglobulin (IVlg) dampens neuronal toll-like receptor-mediated responses in ischemia
}

Ker Zhing Lok ${ }^{1,2}$, Milan Basta ${ }^{3}$, Silvia Manzanero ${ }^{4}$ and Thiruma V Arumugam ${ }^{1,2^{*}}$

\begin{abstract}
Background: Ischemic stroke causes a high rate of deaths and permanent neurological damage in survivors. Ischemic stroke triggers the release of damage-associated molecular patterns (DAMPs) such as high-mobility group box 1 (HMGB1), which activate toll-like receptors (TLRs) and receptor for advanced glycation endproducts (RAGE) in the affected area, leading to an exaggerated inflammatory response and cell death. Both TLRs and RAGE are transmembrane pattern recognition receptors (PRRs) that have been shown to contribute to ischemic stroke-induced brain injury. Intravenous immunoglobulin (IVlg) preparations obtained by fractionating human blood plasma are increasingly being used as an effective therapeutic agent in the treatment of several inflammatory diseases. Its use as a potential therapeutic agent for treatment of stroke has been proposed, but little is known about the direct neuroprotective mechanisms of IVlg. We therefore investigate whether IVlg exerts its beneficial effects on the outcome of neuronal injury by modulating HMGB1-induced TLR and RAGE expressions and activations.
\end{abstract}

Methods: Primary cortical neurons were subjected to glucose deprivation or oxygen and glucose deprivation conditions and treated with IVIg and recombinant HMGB1. C57/BL6J mice were subjected to middle cerebral artery occlusion, followed by reperfusion, and IVIg was administered intravenously $3 \mathrm{~h}$ after the start of reperfusion. Expression of TLRs, RAGE and downstream signalling proteins in neurons and brain tissues were evaluated by immunoblot.

Results: Treatment of cultured neurons with IVIg reduced simulated ischemia-induced TLR2, TLR4, TLR8 and RAGE expressions, pro-apoptotic caspase-3 cleavage and phosphorylation of the cell death-associated kinases such as c-Jun N-terminal kinase (JNK), p38 mitogen-activated protein kinase (MAPK) as well as the p65 subunit of nuclear factor kappa B (NF-KB). These results were recapitulated in an in vivo model of stroke. IVlg treatment also upregulated the anti-apoptotic protein B-cell lymphoma 2 (BCl-2) in cortical neurons under ischemic conditions. Finally, IVlg protected neurons against HMGB1-induced neuronal cell death by modulating TLR and RAGE expressions and signalling pathways.

Conclusions: Taken together, these results provide a rationale for the potential use of IVlg to target inappropriately activated components of the innate immune system following ischemic stroke.

Keywords: TLRs, IVIg, Neuronal death, HMGB1, Ischemic stroke

\footnotetext{
* Correspondence: phstva@nus.edu.sg

'Department of Physiology, Yong Loo Lin School of Medicine, National

University of Singapore, Block MD9, 2 Medical Drive \#04-01, Singapore

117597, Singapore

${ }^{2}$ School of Biomedical Sciences, The University of Queensland, Chancellors PI,

Brisbane QLD 4072, Australia

Full list of author information is available at the end of the article
} 


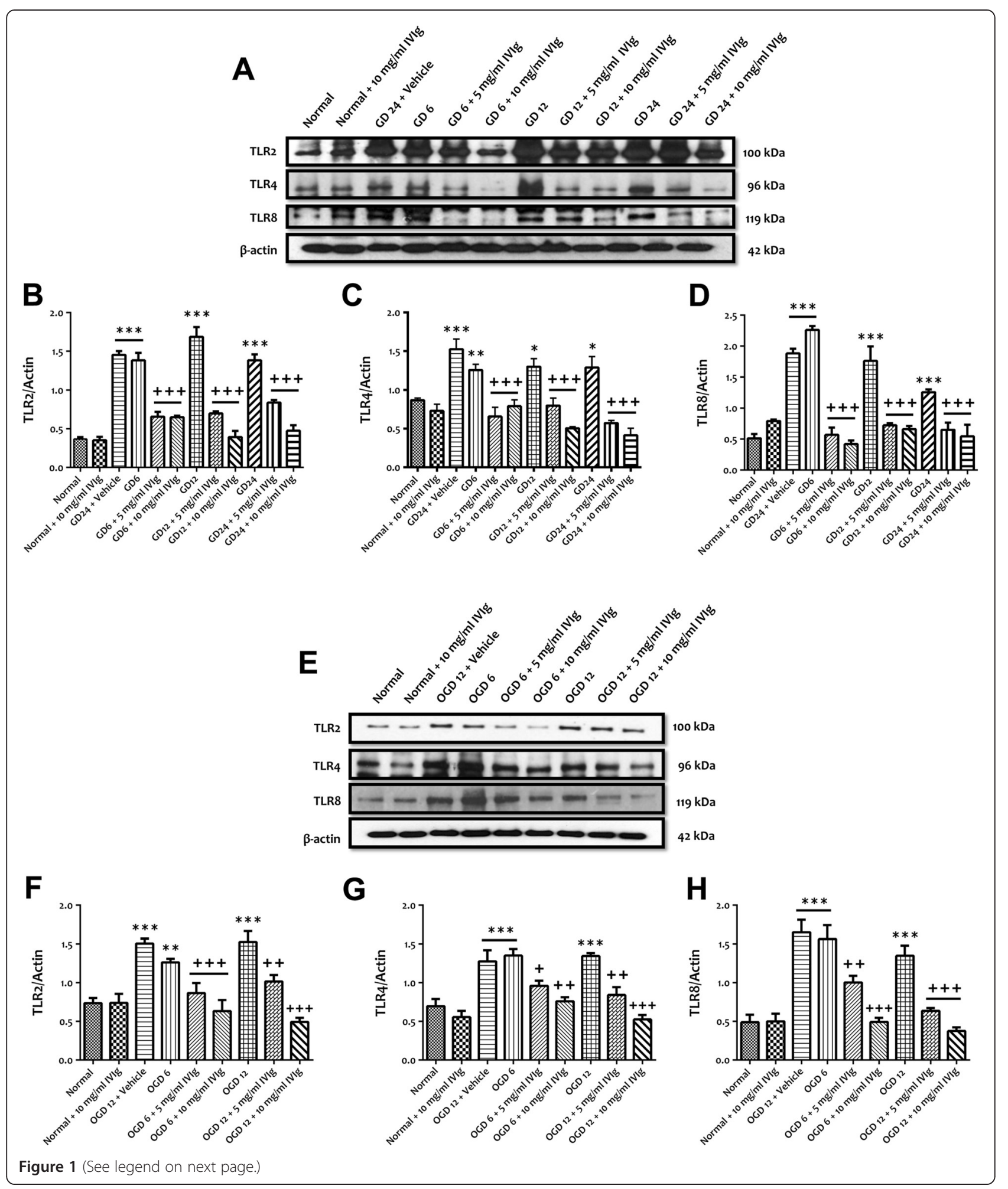


(See figure on previous page.)

Figure $1 \mathrm{IVlg}$ treatment inhibits the increased expressions of TLRs in cultured cortical neurons subjected to simulated ischemia. (A-D) Representative 2immunoblots and quantification illustrating increases in the levels of TLR2, TLR4 and TLR8 proteins in primary cortical neurons at indicated times during GD. Administration of IVlg ( 5 and $10 \mathrm{mg} / \mathrm{ml}$ ) significantly prevents GD-induced increased expression of TLR2, TLR4 and TLR8. Data are represented as mean \pm SEM. $n=5$ cultures. ${ }^{*} P<0.05$ in comparison with normal; ${ }^{* *} P<0.01$ in comparison with normal; ${ }^{* * *} P<0.001$ in comparison with normal; ${ }^{+++} P<0.001$ in comparison with vehicle-treated group. (E-H) Representative immunoblots and quantification illustrating increases in the levels of TLR2, TLR4 and TLR8 proteins in primary cortical neurons at indicated times during OGD. Administration of IVIg (5 and $10 \mathrm{mg} / \mathrm{ml})$ significantly prevents OGD-induced increased expression of TLR2, TLR4 and TLR8. Data are represented as mean \pm SEM. $n=5$ cultures. ${ }^{* *} P<0.01$ in comparison with normal; ${ }^{* * *} P<0.001$ in comparison with normal; ${ }^{+} P<0.05$ in comparison with vehicle-treated group; ${ }^{++} P<0.01$ in comparison with vehicle-treated group; ${ }^{+++} P<0.001$ in comparison with vehicle-treated group.

\section{Background}

Toll-like receptors (TLRs) are expressed in a variety of mammalian immune-related cell types and initiate signals in response to diverse pathogen-associated molecular patterns (PAMPs) [1]. The signalling pathways activated by the TLRs are broadly classified into MyD88-dependent and -independent pathways [2]. Upon receptor activation and interaction with MyD88, one or more of the toll/ interleukin-1 receptor (TIR)-containing adapter proteins are recruited and MyD88 binds with the TIR domain of the receptor and phosphorylates interleukin-1 receptorassociated kinase 4 (IRAK4), which, in turn, phosphorylates IRAK1. After being phosphorylated, IRAK1 dissociates from MyD88 and interacts with TRAF6. TRAF6 forms a complex that activates downstream signalling of TLRs [1]. Major downstream signalling pathways activated by TLR engagement include the nuclear factor kappa B (NF$\mathrm{\kappa B})$ and mitogen-activated protein kinases (MAPKs) such as c-Jun N-terminal kinase (JNK) and p38 MAPK cascades. The MyD88-independent pathway signals through the adaptor TIR-domain-containing adaptor protein inducing interferon (IFN)- $\beta$-mediated transcription factor (TRIF) [1]. TRIF interacts with TRAF3 leading to the recruitment and activation of tumour necrosis factor (TNF) receptor-associated factor-family member-associated NF- $\kappa B$ activator-binding kinase 1 (TBK1) and inhibitor of nuclear factor kappa-B kinase subunit epsilon (IKKe). This culminates in interferon regulatory factor 3 (IRF3) phosphorylation that facilitates IRF3 dimerization and translocation into the nucleus and transcriptional regulation. In relation to cerebral ischemia, it has been shown that disruption of downstream MyD88-independent (TRIF) TLR pathway does not confer protection in in vitro and in vivo models of cerebral ischemia [3]. A variety of endogenous ligands, such as high-mobility group box 1 (HMGB1), also bind to TLR and activate several intracellular inflammatory pathways, including the NF- $\mathrm{KB}$, JNK and p38 MAPK pathways $[4,5]$. The presence of several TLRs has been reported in the brain, both in glial and neuronal cells [6-9], and recent studies have reported the pathological roles of TLR2, TLR4 and TLR8 in ischemic stroke-induced brain injury [7,9-12]. Neurons were found to express TLR2, TLR4 and TLR8 under both physiological and pathological conditions, and cortical neuronal cultures from both TLR2 and TLR4 deficient mice were protected against cell death induced by energy deprivation (an in vitro model of ischemic stroke) when compared with wild type [7]. Furthermore, we have recently provided evidence that neuronal TLR8 signalling plays a detrimental role by triggering post-stroke inflammation and neuronal cell death [9].

Intravenous immunoglobulin (IVIg) is an FDA-approved therapeutic modality used for various autoimmune and inflammatory diseases [13]. Recently, we demonstrated that IVIg treatment significantly reduced brain infarct volume and mortality in an experimental mouse model of ischemic stroke $[14,15]$. IVIg has also been shown to inhibit complement activation, modulate cytokine production, reduce endothelial dysfunction and death, reduce activation and infiltration of leukocytes, as well as inhibit neuronal apoptosis by decreasing the cleavage of caspase- 3 in primary cortical neurons subjected to ischemic insults $[14,15]$. It was recently shown that IVIg may modulate TLR9 expression and activation in pathological conditions such as systemic lupus erythematosus (SLE), suggesting a new additional mechanism of IVIg [16]. IVIg has also been shown to modulate the maturation of TLR-primed peripheral blood monocytes [17]. In addition, IVIg suppresses TLR4-induced cytokine production induced by lipopolysaccharide (LPS) by inhibiting the NF-kB, JNK and p38 MAPK pathways in human monocytic cells [18]. IVIg also attenuates multiple cell death pathways by decreasing the phosphorylation of the p65 subunit of NF-kB, JNK, p38 MAPK and c-Jun, in simulated ischemic condition [15]. However, relatively little is known about the role of IVIg in modulating the expression and activation of TLRs and endogenous ligand-mediated TLR activation following ischemic stroke. Here, we provide the first evidence that IVIg protects neurons by decreasing the expression and activation of TLRs and by suppressing HMGB1-mediated TLR activation. Our findings further support IVIg as a potential therapeutic modality for targeting ischemic strokeinduced neuronal cell death and brain injury.

\section{Methods}

Primary cortical neuronal cultures

Dissociated neuron-enriched cell cultures of mouse cerebral cortex were established from day 16 C57BL/6 J mouse 

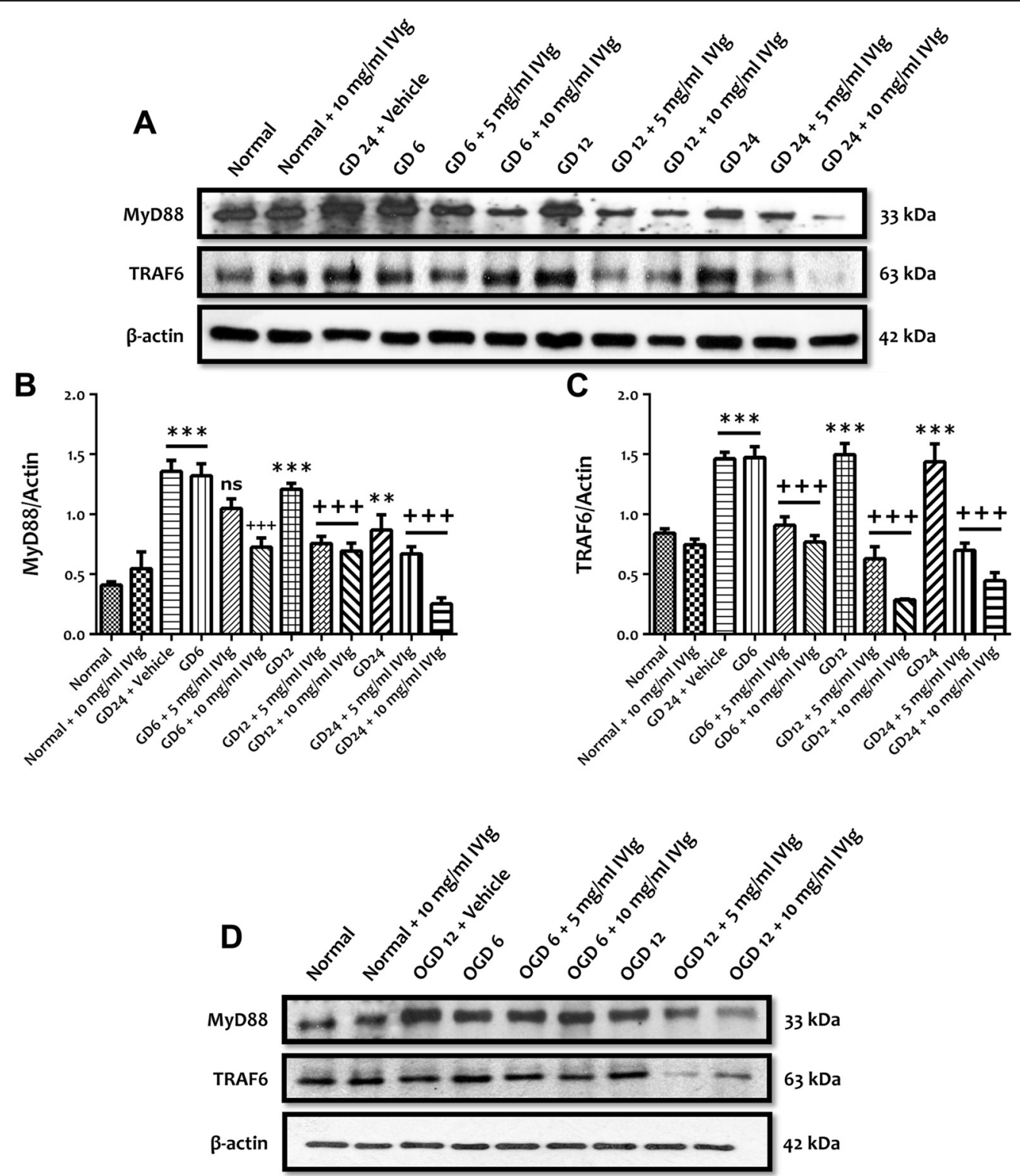

E

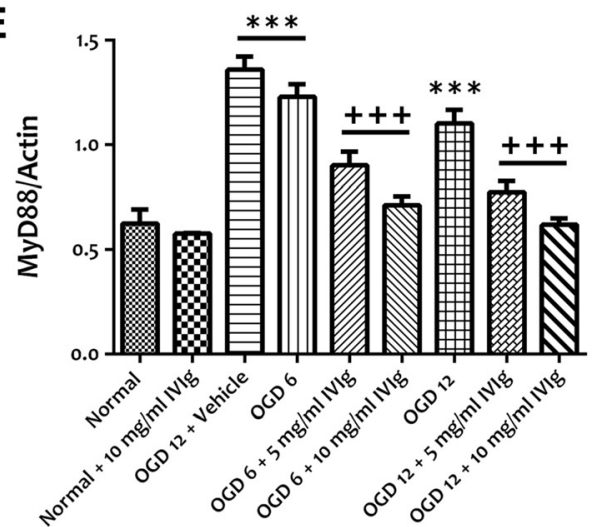

F

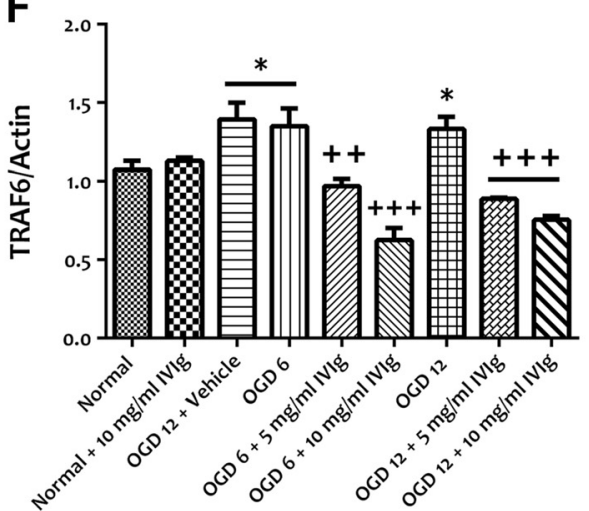

Figure 2 (See legend on next page.) 
(See figure on previous page.)

Figure $2 \mathrm{IVlg}$ treatment prevents the increased expressions of TLR adaptor and signalling proteins. IVlg treatment prevents the increased expressions of TLR adaptor and signalling proteins in cultured cortical neurons subjected to simulated ischemia. (A-C) Representative immunoblots and quantification illustrating increases in the levels of MyD88 and TRAF6 proteins in primary cortical neurons at indicated times during GD. Administration of $10 \mathrm{mg} / \mathrm{ml}$ of IVlg significantly prevents the increase in MyD88 and TRAF6 protein expression caused by 6,12 and 24 h of $\mathrm{GD}$; the effect of $5 \mathrm{mg} / \mathrm{ml} \mathrm{IVlg}$ was significant at 12 and 24 , but not $6 \mathrm{~h}$ of GD. Data are represented as mean \pm SEM. $n=5$ cultures. ${ }^{* *} P<0.01$ in comparison with normal; ${ }^{* * *} P<0.001$ in comparison with normal; ${ }^{+++} P<0.001$ in comparison with vehicle-treated group; ns, not significant. (D-F) Representative immunoblots and quantification illustrating increases in the levels of MyD88 and TRAF6 proteins in primary cortical neurons at indicated times during OGD. Administration of $\mathrm{IVIg}(5$ and $10 \mathrm{mg} / \mathrm{ml}$ ) significantly prevents an increased expression level of MyD88 and TRAF6 proteins following 6 and $12 \mathrm{~h}$ of OGD. Data are represented as mean \pm SEM. $n=5$ cultures. ${ }^{*} P<0.05$ in comparison with normal; ${ }^{* * *} P<0.001$ in comparison with normal; ${ }^{++} P<0.01$ in comparison with vehicle-treated group; ${ }^{+++} P<0.001$ in comparison with vehicle-treated group.

embryos, as previously described [19]. Experiments were performed in 7- to 9-day-old cultures. Approximately $95 \%$ of the cells in such cultures were neurons, and the remaining cells were astrocytes.

\section{Glucose deprivation and combined oxygen-glucose deprivation}

For glucose deprivation (GD) studies, glucose-free Locke's buffer containing: $154 \mathrm{mM} \mathrm{NaCl}, 5.6 \mathrm{mM} \mathrm{KCl}, 2.3 \mathrm{mM}$ $\mathrm{CaCl}_{2}, 1 \mathrm{mM} \mathrm{MgCl}$, $3.6 \mathrm{mM} \mathrm{NaHCO} 3,5 \mathrm{mM}$ HEPES, $\mathrm{pH}$ 7.2, supplemented with gentamicin $(5 \mathrm{mg} / \mathrm{L})$ was used. The cultured neurons were incubated in glucose-free Locke's buffer for up to $24 \mathrm{~h}$. For combined oxygen and glucose deprivation (OGD) studies, neurons were incubated in glucose-free Locke's buffer in an oxygen-free chamber for 4.5, 6 or $12 \mathrm{~h}$. To observe the effect of IVIg, IVIg (KIOVIG, Baxter) was added at the reported concentrations to the cultures during GD or OGD conditions. The active ingredient in KIOVIG is a human plasmaderived immunoglobulin, concentration of $100 \mathrm{mg} / \mathrm{mL}$ $(10 \% \mathrm{w} / \mathrm{v})$, produced from large pools of human plasma by a modified Cohn-Oncley cold ethanol fractionation, yielding an intermediate immunoglobulin $\mathrm{G}$, referred to as precipitate G. Equal concentration of glycine (Sigma Aldrich, St. Louis, MO, USA), an amino acid with no known affinity for any cell receptors, was also included in the experiments as vehicle control for IVIg. To observe the effect of HMGB1, mouse recombinant HMGB1 (Source: E. coli expressed amino acids Met1-Glu215 of mouse HMGB-1 accession \# NM_010439; purity: >98\%; endotoxin: less than $0.01 \mathrm{ng} / \mu \mathrm{g}$ cytokine) (34-8401, eBioscience, San Diego, CA, USA) was added either alone or simultaneously with IVIg to the OGD-treated neuronal cultures.

\section{Western blot analysis}

Protein samples were subjected to sodium dodecyl sulphatepolyacrylamide $(7.5 \%$ or $10 \%)$ gel electrophoresis using a Tris-glycine running buffer (Bio-Rad, Hercules, CA, USA). Gels were then electro-blotted using a semi-dry transfer apparatus (Bio-Rad) in transfer buffer containing $0.025 \mathrm{~mol} / \mathrm{L}$ Tris base, $0.15 \mathrm{~mol} / \mathrm{L}$ glycine and $10 \%(\mathrm{v} / \mathrm{v})$ methanol for $1.5 \mathrm{~h}$ at $350 \mathrm{~mA}$ onto nitrocellulose membranes (Bio-Rad).
The membranes were then incubated in blocking buffer $[5 \%$ bovine serum albumin (BSA) or $5 \%$ non-fat milk in TBS-T (20 mmol/L Tris- $\mathrm{HCl}, \mathrm{pH} 7.5,137 \mathrm{mmol} / \mathrm{L} \mathrm{NaCl}, 0.2 \%$ Tween-20)] for $1 \mathrm{~h}$ at room temperature. The membranes were then incubated overnight at $4^{\circ} \mathrm{C}$ with primary antibodies including those that selectively bind TLR2 (Abcam, Cambridge, UK), TLR4 (Abcam), TLR8 (Abcam), RAGE (Abcam), MyD88 (Abcam), TRAF6 (Abcam), p-JNK (Cell Signaling, Danvers, MA, USA), p-p38 MAPK (Cell Signaling), p-p65 (Cell Signaling), p-c-Jun (Cell Signaling), Bcl-2 (Cell Signaling), cleaved caspase-3 (Cell Signaling), HMGB1 (Cell Signaling) and $\beta$-actin (Sigma Aldrich). After washing three times (10 min per wash) with TBS$\mathrm{T}$, the membranes were incubated with horseradish peroxidase-conjugated secondary antibodies for $1 \mathrm{~h}$ at room temperature. The membranes were then washed again with TBS-T and incubated with chemiluminescent substrate for enhanced chemiluminescence (Thermo Fisher Scientific, Waltham, MA, USA) for $5 \mathrm{~min}$. The signals were visualized by exposing the membranes onto X-ray films (Fujifilm Corporation, Minato, Tokyo, Japan).

\section{Middle cerebral artery occlusion and reperfusion}

12- to 14-week-old C57BL/6 J male mice were used for in vivo experiments. The focal cerebral ischemia/reperfusion (I/R) model was similar to that described previously [20]. Briefly, the mice were anesthetized with isoflurane, a midline incision was made in the neck, and the left external carotid and pterygopalatine arteries were isolated and ligated with 6-0 silk thread. The internal carotid artery (ICA) was occluded at the peripheral site of the bifurcation of the ICA and the pterygopalatine artery using a small clip, and the common carotid artery (CCA) was ligated with 6-0 silk thread. The external carotid artery (ECA) was cut, and a 6-0 nylon monofilament with a blunted tip (0.2 to $0.22 \mathrm{~mm}$ ) with a coagulator was inserted into the ECA. After the clip at the ICA was removed, the nylon monofilament was advanced into the origin of the middle cerebral artery (MCA) until light resistance was felt. The nylon monofilament and the CCA ligature were removed after $1 \mathrm{~h}$ of occlusion to initiate reperfusion. In the sham-operated group, these arteries were visualized but not disturbed. Mice were administered with $1 \mathrm{~g} / \mathrm{kg}$ body 

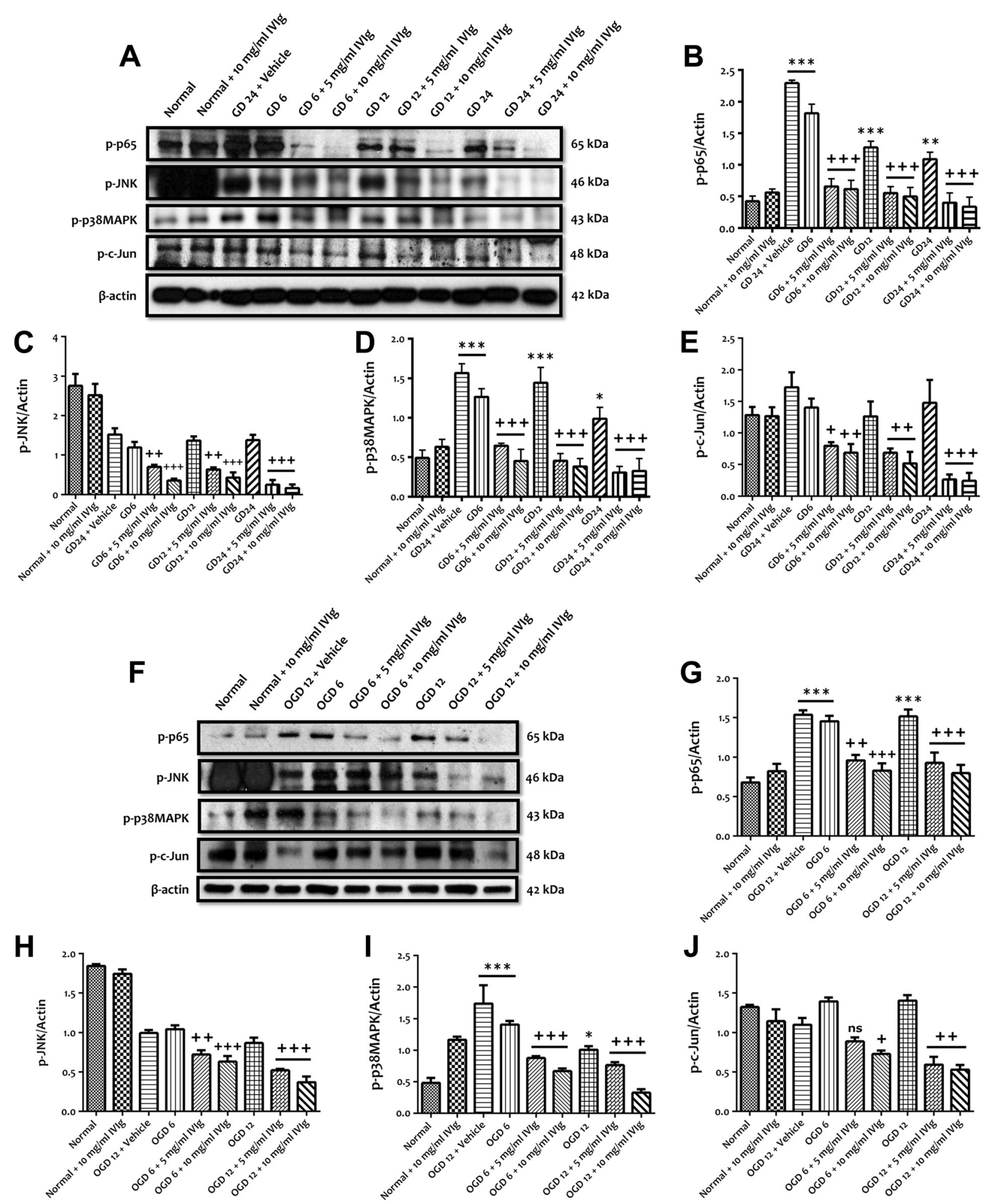

Figure 3 (See legend on next page.) 


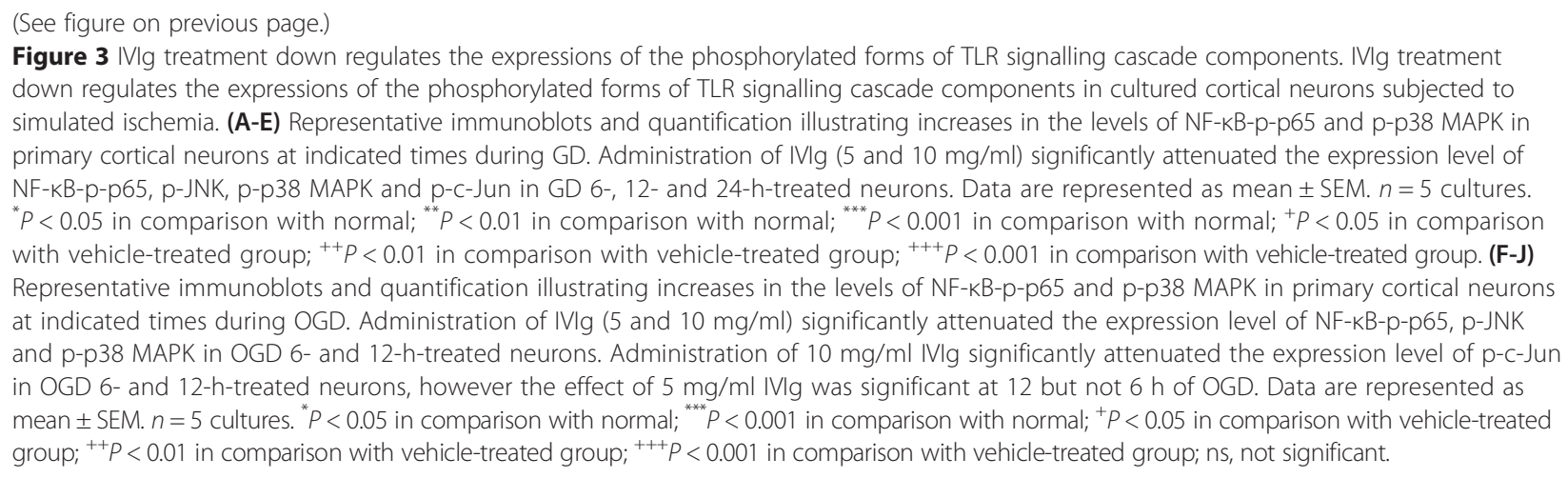

weight of IVIg or vehicle by infusion into the femoral vein (approximately $250 \mu \mathrm{L}$ ) $3 \mathrm{~h}$ after the start of reperfusion period. Cerebral blood flow was measured by placing the animal's head in a fixed frame after it had been anesthetized and prepared for surgery. A craniotomy was performed to access the left middle cerebral artery and was extended to allow positioning of a $0.5-\mathrm{mm}$ Doppler probe (Moor LAB, Moor Instruments, Devon, UK) over the underlying parietal cortex approximately $1 \mathrm{~mm}$ posterior to the bregma and $1 \mathrm{~mm}$ lateral to the midline. The animals were included in the study if they underwent successful MCA occlusion, defined by an $80 \%$ or greater drop in cerebral blood flow seen with laser Doppler flowmetry. The animals were excluded if insertion of the thread resulted in perforation of the vessel wall determined by the presence of sub-arachnoid blood at the time of sacrifice. University of Queensland Animal Care and Use Committee approved all in vivo experimental procedures.

\section{Statistical analysis}

All numerical values are expressed as mean \pm SEM. The overall significance of the data was examined by one-way analysis of variance (ANOVA) followed by Newman-Keuls post hoc test to determine group differences. Statistical difference was considered as $P<0.05$ throughout the study. Statistical analyses were performed using GraphPad Prism software.

\section{Results}

IVIg treatment reduces expression and activation of TLRs in primary cortical neurons subjected to GD and OGD conditions

We first evaluated the effect of IVIg on the protein expressions of TLR2, TLR4 and TLR8 in a cell culture model of ischemic neuronal injury in which primary mouse cortical neurons were subjected to conditions mimicking ischemic stroke, including glucose deprivation (GD) and combined oxygen and glucose deprivation (OGD) (Figure 1). We have previously shown that low concentrations ( 0.1 and $0.3 \mathrm{mg} / \mathrm{ml}$ ) of IVIg significantly increased in vitro ischemic stress-induced neuronal cell death whereas high concentrations (5 and $10 \mathrm{mg} / \mathrm{ml}$ ) of IVIg significantly decreased GD-induced neuronal cell death [15]. Therefore, we used 5 and $10 \mathrm{mg} / \mathrm{ml}$ in this study to test the effect of IVIg against TLR expression and activation. Immunoblot analyses showed that treatment with IVIg ( 5 and $10 \mathrm{mg} / \mathrm{ml}$ ) significantly prevented GD-induced increased expressions of TLR2, TLR4 and TLR8 following 6, 12 and $24 \mathrm{~h}$ (Figure 1A-D). Treatment with IVIg ( 5 and $10 \mathrm{mg} / \mathrm{ml}$ ) also significantly prevented 6 and 12 h OGD-induced increased neuronal expressions of TLR2, TLR4 and TLR8 (Figure 1E-H). We next analysed the effect of IVIg on the expression levels of myeloid differentiation primary response gene (88) (MyD88) and TNF receptor-associated factor 6 (TRAF6) following GD and OGD conditions. Both of these proteins are involved in the downstream signalling of TLR2, TLR4 and TLR8. Our immunoblot analyses showed that GD- and OGD-induced upregulation of MyD88 and TRAF6 levels at different time points was significantly prevented by IVIg treatment (Figure 2A-F).

\section{IVIg modulates neuronal NF-KB and MAPK activities and protects neurons against apoptotic cell death following simulated ischemic condition}

Because the activation of NF- $\mathrm{kB}$, JNK and p38 MAPK pathways are implicated in TLR2, TLR4 and TLR8 signalling and ischemia-induced neuronal cell death [10,21], we next measured the protein levels of phosphorylated p65 (a subunit of NF-kB), JNK, p38 MAPK and c-Jun following GD and OGD in IVIg-treated neurons compared with control neurons. Treatment with both 5 and $10 \mathrm{mg} / \mathrm{ml}$ of IVIg significantly attenuated the expression level of the phosphorylated forms of NF-kB p65 (Figure 3A,B), JNK, p38 MAPK and c-Jun following 6, 12 and $24 \mathrm{~h}$ of GD when compared to the vehicletreated group (Figure 3A,C-E). We also measured the levels of these proteins under OGD conditions. Immunoblot analyses showed that IVIg treatments attenuated the expression level of the phosphorylated forms of NF-kB 

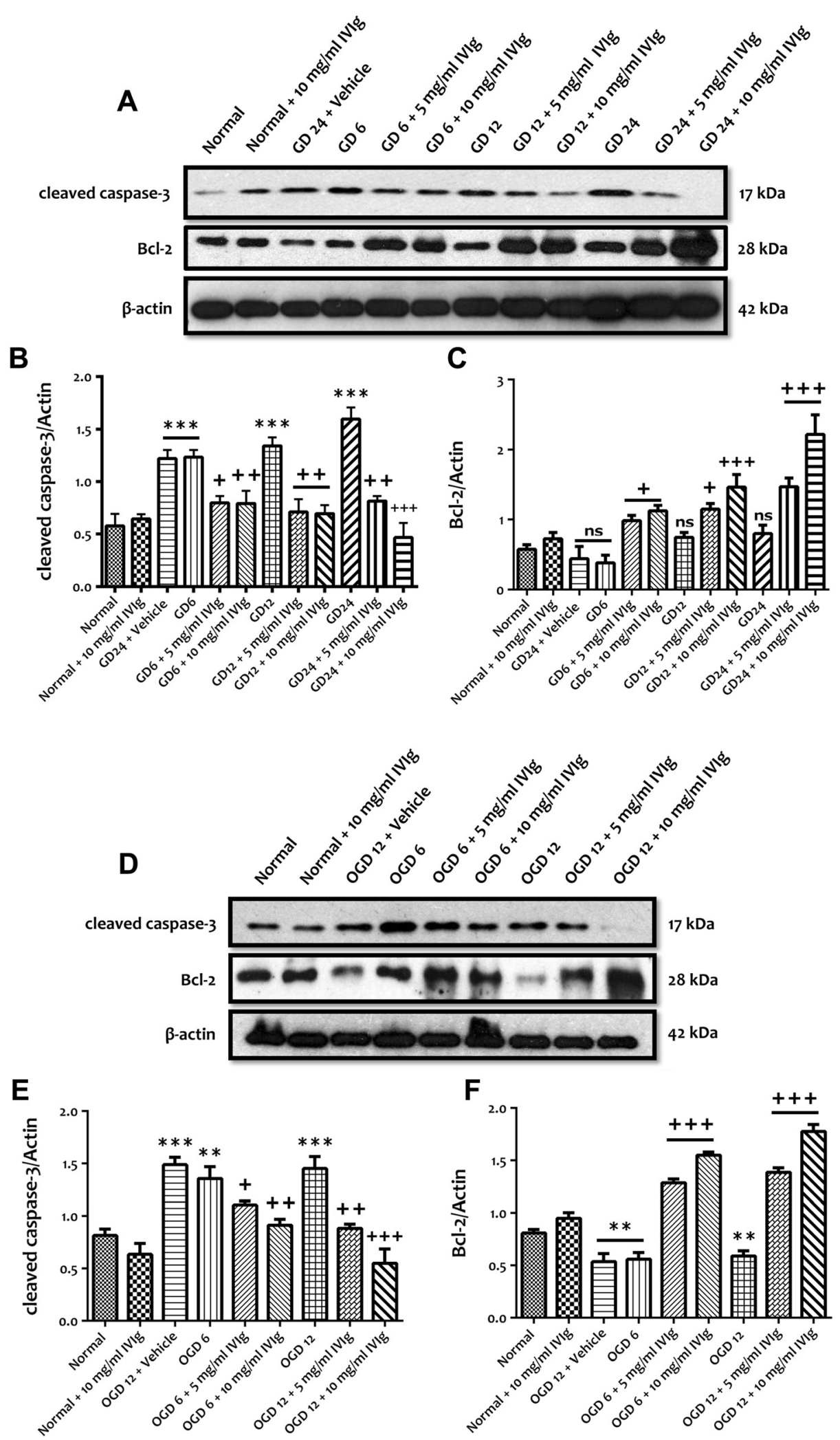

Figure 4 (See legend on next page.) 
(See figure on previous page.)

Figure $4 \mathrm{IVlg}$ protects cultured neurons against simulated ischemia. (A, B) Treatment with high concentrations of IVlg (5 and 10 mg/ml) significantly prevents GD-induced increased expression of pro-apoptotic cleaved caspase-3 following 6,12 and 24 h. Data are represented as mean \pm SEM. $n=5$ cultures. ${ }^{* * *} P<0.001$ in comparison with normal; ${ }^{+} P<0.05$ in comparison with vehicle-treated group; ${ }^{++} P<0.01$ in comparison with vehicle-treated group; ${ }^{+++} P<0.001$ in comparison with vehicle-treated group. (A, C) Treatment with high concentrations of IVlg (5 and $\left.10 \mathrm{mg} / \mathrm{mL}\right)$ significantly increased the expression level of anti-apoptotic Bcl-2 following 6, 12 and $24 \mathrm{~h}$ of GD. Data are represented as mean \pm SEM. $n=5$ cultures. ${ }^{+} P<0.05$ in comparison with vehicle-treated group; ${ }^{+++} P<0.001$ in comparison with vehicle-treated group; ns, not significant. (D, E) Treatment with high concentrations of IVlg ( 5 and $10 \mathrm{mg} / \mathrm{mL}$ ) significantly prevents OGD-induced increased expression of pro-apoptotic cleaved caspase-3 following 6 and 12 h. Data are represented as mean \pm SEM. $n=5$ cultures. ${ }^{* *} P<0.01$ in comparison with normal; ${ }^{* * *} P<0.001$ in comparison with normal; ${ }^{+} P<0.05$ in comparison with vehicle-treated group; ${ }^{++} P<0.01$ in comparison with vehicle-treated group; ${ }^{+++} p<0.001$ in comparison with vehicle-treated group. (D, F) Treatment with high concentrations of IVlg (5 and $10 \mathrm{mg} / \mathrm{mL}$ ) significantly prevents a decreased level of anti-apoptotic $\mathrm{BCl}-2$ following 6 and $12 \mathrm{~h}$ of OGD. Data are represented as mean \pm SEM. $n=5$ cultures. ${ }^{* *} P<0.01$ in comparison with normal; ${ }^{+++} P<0.001$ in comparison with vehicle-treated group.

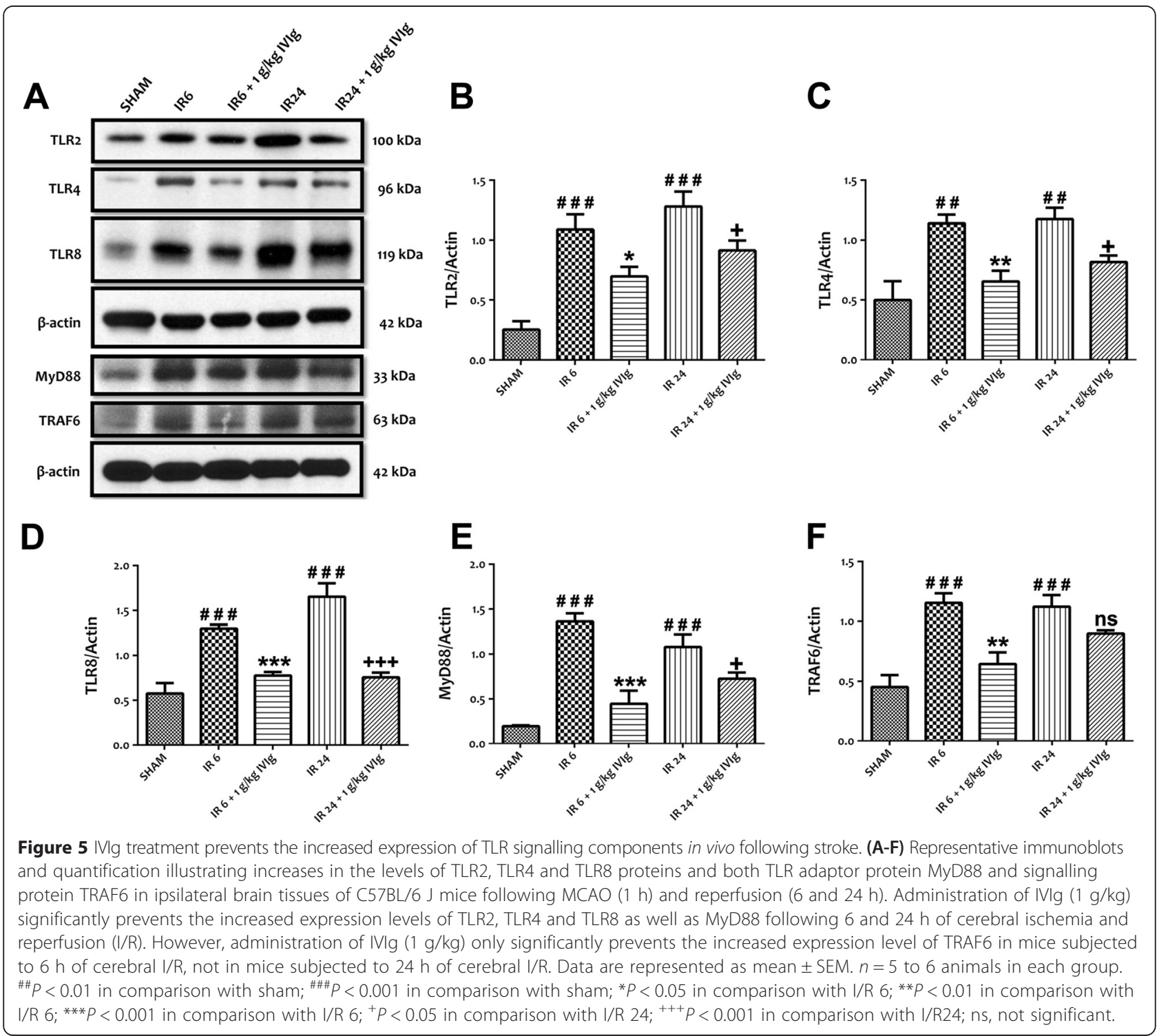




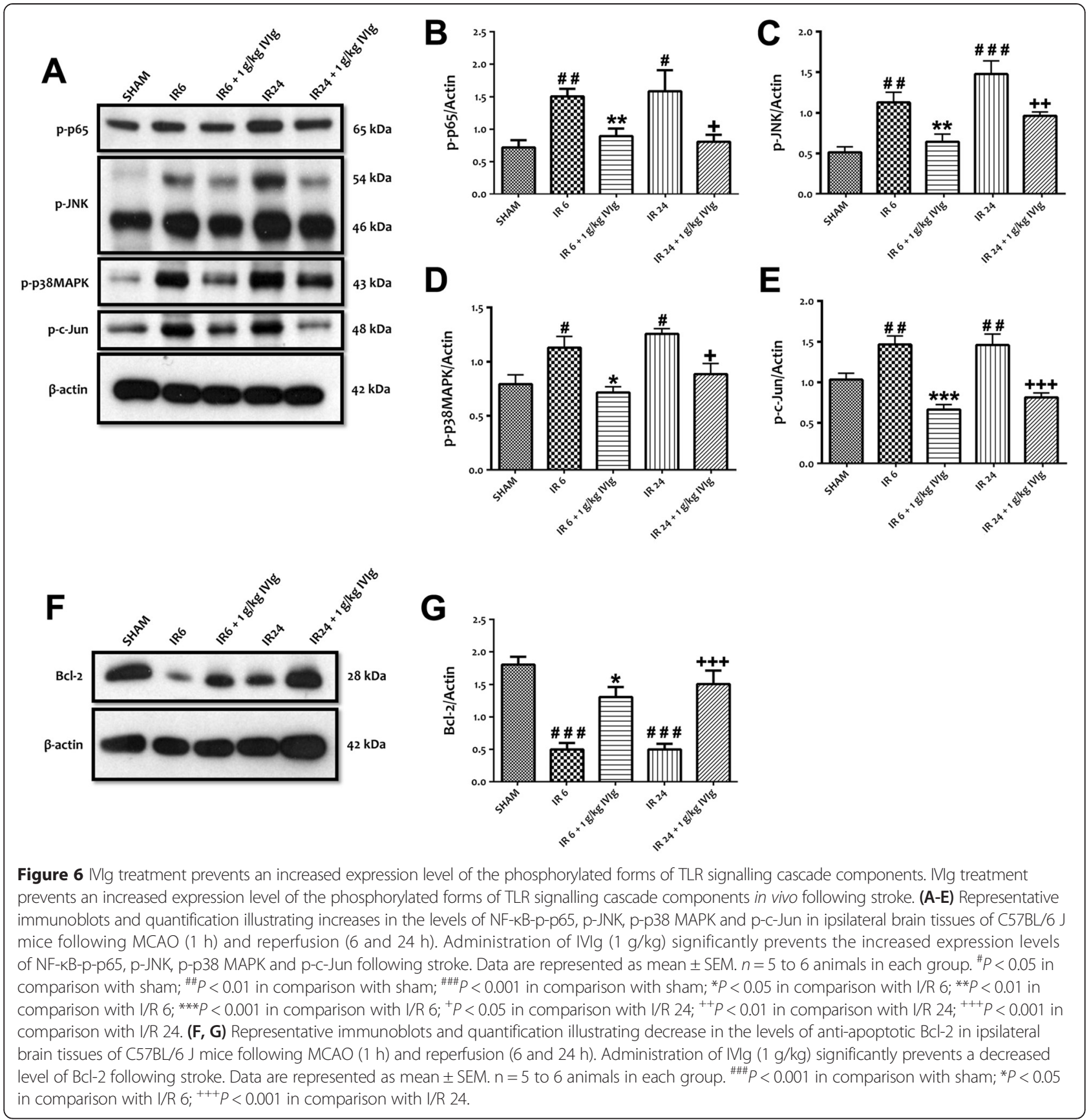

p65, JNK, p38 MAPK and c-Jun following 6 and $12 \mathrm{~h}$ of OGD, however statistical significance was not reached for the expression level of phosphorylated cJun in neurons treated with $5 \mathrm{mg} / \mathrm{ml}$ of IVIg following $6 \mathrm{~h}$ of OGD (Figure 3F-J). Consistent with our previous findings, the immunoblot results showed that IVIg treatment significantly prevented an increased expression of cleaved caspase- 3 and significantly increased the expression of $\mathrm{Bcl}-2$ in primary cortical neurons following 6, 12 and $24 \mathrm{~h}$ of GD (Figure 4A-C). Similarly, we have also observed that IVIg treatment significantly prevented an increased expression of cleaved caspase- 3 and significantly prevented a decreased expression of Bcl-2 in OGD 6- and 12-h-treated neurons (Figure 4D-F). These results not only confirm our previously published data following GD conditions but also show for the first time that IVIg can protect neurons following OGD conditions by downregulating apoptosis and upregulating the anti-apoptotic protein, Bcl-2. 


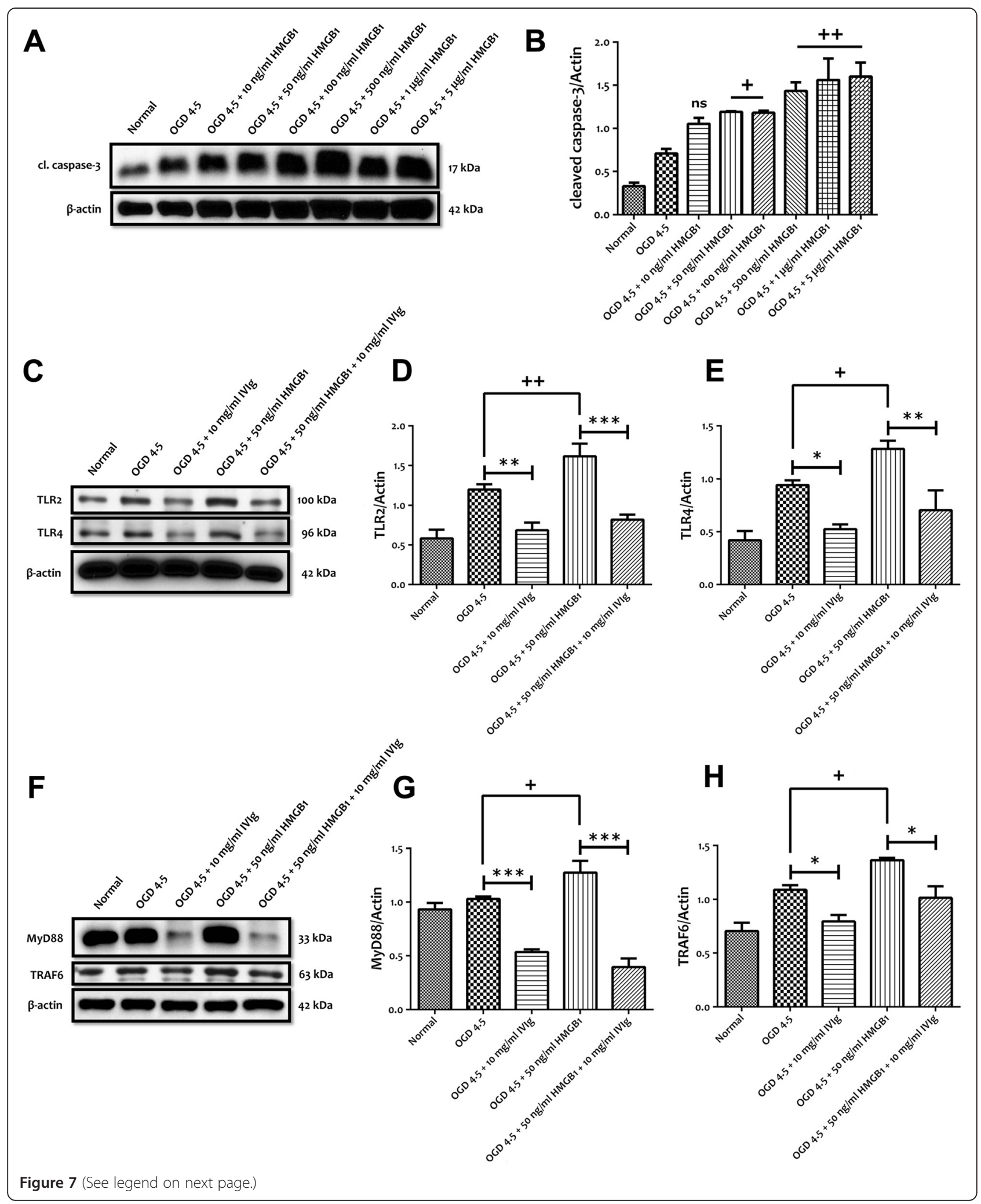


(See figure on previous page.)

Figure $7 \mathrm{IVlg}$ protects primary neurons against HMGB1-induced cell death by modulating TLRs expression. (A, B) Different concentrations of mouse recombinant HMGB1 significantly increase oxygen and glucose deprivation (OGD)-induced pro-apoptotic cleaved caspase-3 level. Data are represented as mean \pm SEM. $n=3$ cultures. ${ }^{+} P<0.05$ in comparison with OGD 4.5 -h group; ${ }^{++} P<0.01$ in comparison with OGD 4.5-h group; ns, not significant. (C-E) Representative immunoblots and quantification illustrating HMGB1 increases the levels of TLR2 and TLR4 in primary cortical neurons following $4.5 \mathrm{~h}$ of OGD. Administration of IVlg $(10 \mathrm{mg} / \mathrm{ml})$ significantly prevents HMGB1-induced increased expression level of TLR2 and TLR4. Data are represented as mean \pm SEM. $n=5$ cultures. ${ }^{+} P<0.05$ in comparison with OGD 4.5 -h group; ${ }^{++} P<0.01$ in comparison with OGD 4.5-h group; ${ }^{*} P<0.05$ in comparison with corresponding OGD group; ${ }^{* *} P<0.01$ in comparison with corresponding OGD group; ${ }^{* * *} P<0.001$ in comparison with corresponding OGD group. (F-H) Representative immunoblots and quantification illustrating HMGB1 increases the levels of MyD88 and TRAF6 in primary cortical neurons following $4.5 \mathrm{~h}$ of OGD. Administration of IVlg $(10 \mathrm{mg} / \mathrm{ml})$ significantly prevents HMGB1-induced increased expression level of MyD88 and TRAF6. Data are represented as mean \pm SEM. $n=5$ cultures. ${ }^{+} P<0.05$ in comparison with OGD 4.5 -h group; * $P<0.05$ in comparison with corresponding OGD group; ${ }^{* *} P<0.001$ in comparison with corresponding OGD group.

IVIg reduces the expression and activation of TLRs as well as NF-кB and MAPK activities in vivo following stroke

We previously reported that pre- and post-treatment with IVIg reduced brain damage and neurological deficits after cerebral I/R in mice [14]. However, we do not know if the IVIg-mediated protective effect in vivo is partly achieved by modulating TLR expression and activation. Therefore, we next analysed the expression of TLR2, TLR4 and TLR8 in vivo following cerebral I/R injury. Our data showed that 6 and $24 \mathrm{~h}$ of cerebral I/R-induced increased expressions of TL2, TLR4 and TLR8 were significantly prevented by post-treatment with $1 \mathrm{~g} / \mathrm{kg}$ body weight of IVIg $3 \mathrm{~h}$ after the onset of reperfusion (Figure 5A-D). We next analysed the expression levels of TLR adaptor and signalling proteins, MyD88 and TRAF6 following cerebral I/R. Similar to the in vitro findings, we observed that 3 -h post-treatment with $1 \mathrm{~g} / \mathrm{kg}$ of IVIg significantly prevented an increased expression level of MyD88 following 6- and 24-h cerebral I/R injury (Figure 5A,E). A $1 \mathrm{~g} / \mathrm{kg}$ of IVIg treatment significantly prevented an increased expression level of TRAF6 following 6-h cerebral I/R injury, however statistical significance was not reached following 24-h cerebral I/R injury (Figure 5A,F). We next analysed the activity of TLR downstream signalling proteins such as NF- $\mathrm{kB}$ and MAPKs in vivo following cerebral I/R injury. IVIg treatment significantly prevented an increased expression level of phosphorylated NF- $\mathrm{kB}$ p65 (Figure 6A,B), JNK, p38 MAPK and c-Jun following 6- and 24-h cerebral I/R as compared with control group (Figure 6A,C-E). Immunoblot analyses showed that IVIg treatment significantly prevented a decreased level of Bcl-2 following both 6- and 24-h cerebral I/R as compared with control group (Figure 6F,G).

\section{IVlg protects neurons against HMGB1-induced cell death by modulating TLR signalling}

High-mobility group box 1 (HMGB1) is a nuclear protein and has different roles, both intracellularly and extracellularly. Nuclear HMGB1 regulates chromatin structure and gene transcription whereas extracellular HMGB1 has shown to bind to receptor for advanced glycation endproducts (RAGE) and the TLRs [22,23]. In order to investigate the effect of IVIg against HMGB1-mediated TLR signalling in neurons following OGD, we first determined the effective concentration of mouse recombinant HMGB1. Our data showed that HMGB1 above $50 \mathrm{ng} / \mathrm{ml}$ was capable of significantly increasing neuronal cleavage of caspase- 3 after $4.5 \mathrm{~h}$ of OGD (Figure 7A,B). We next analysed the effect of IVIg against HMGB1-mediated TLR expression following OGD. Our data showed that both TLR2 and TLR4 expression levels were significantly increased following HMGB1 treatment when compared to OGD alone (Figure 7C-E). Furthermore, HMGB1-induced increase in TLR2 and TLR4 expressions was significantly prevented by $10 \mathrm{mg} / \mathrm{ml}$ of IVIg treatment (Figure 7C-E). Similarly, the levels of MyD88 and TRAF6 were significantly increased with the addition of HMGB1 to OGD cultures and IVIg significantly prevented HMGB1-induced increase in MyD88 and TRAF6 following OGD condition (Figure 7F-H). Next, we analysed HMGB1-mediated TLR signalling pathways following IVIg treatment. Our data showed that the levels of NF-kB-p-p65, p-JNK, p38 MAPK and $\mathrm{p}$-c-Jun expressions were significantly increased following HMGB1 treatment when compared to OGD alone (Figure 8A-F). IVIg significantly prevented HMGB1induced increases of these proteins following OGD condition (Figure 8A-F). In addition, our data showed that OGD-induced cleaved caspase-3 level was significantly increased in the presence of HMGB1 and this increase was significantly prevented with IVIg treatment (Figure 8G,H). Furthermore, the decreased expression level of Bcl-2 was also prevented by IVIg treatment following HMGB1 treatment (Figure 8G,I). Finally, we analysed the total cellular HMGB1 and RAGE expression levels. Our data showed that IVIg treatment resulted in preserving HMGB1 level (Figure 8J,K). Similar to TLRs, RAGE expression level was significantly increased following HMGB1 treatments compared to OGD alone (Figure 8J,L) and HMGB1-induced increase in RAGE expression was significantly prevented by $10 \mathrm{mg} / \mathrm{ml}$ of IVIg treatment (Figure 8J,L).

\section{Discussion}

IVIg therapy has been shown to be effective in the treatment of various inflammatory and autoimmune disorders [24]. Several mechanisms have been proposed to explain 


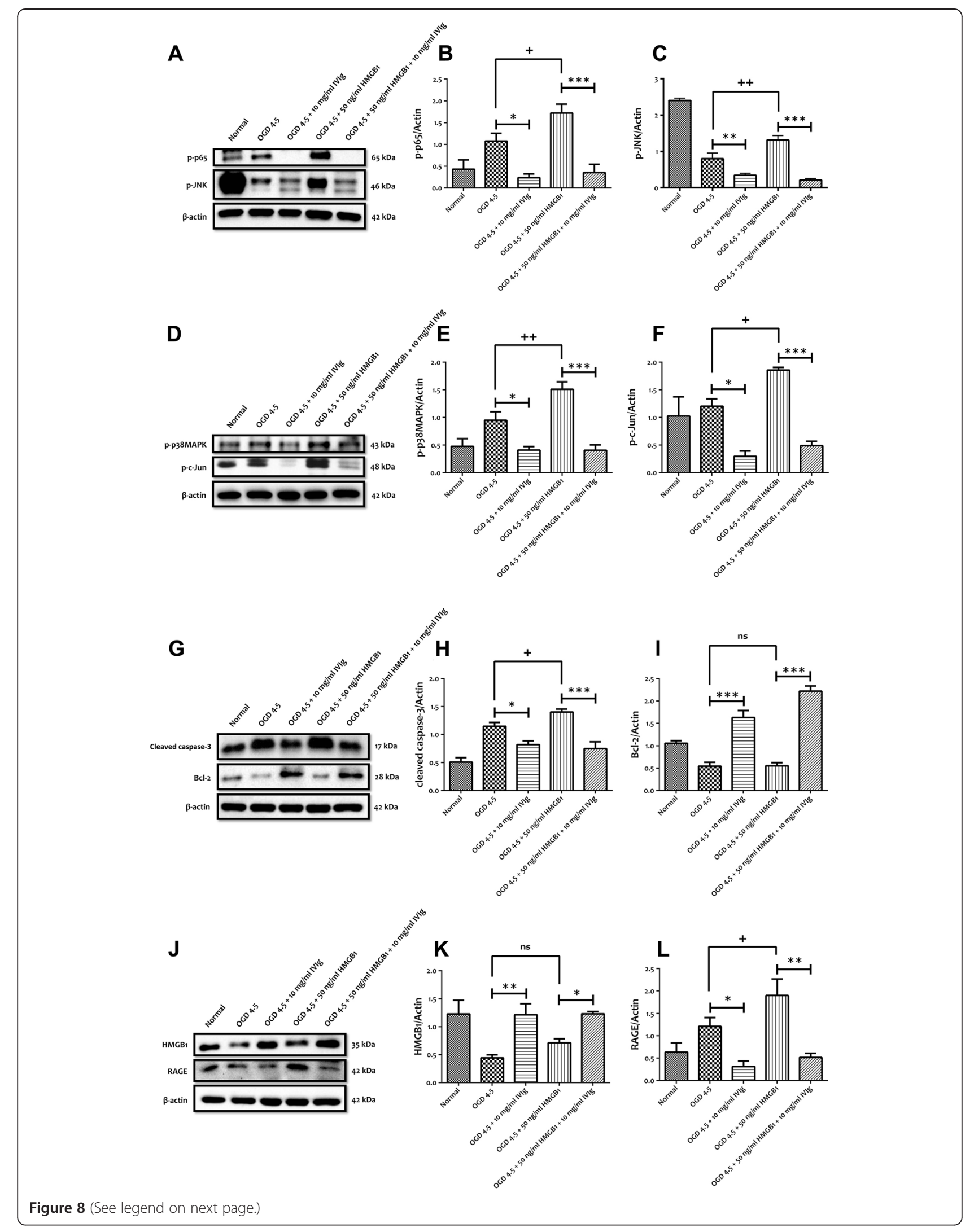




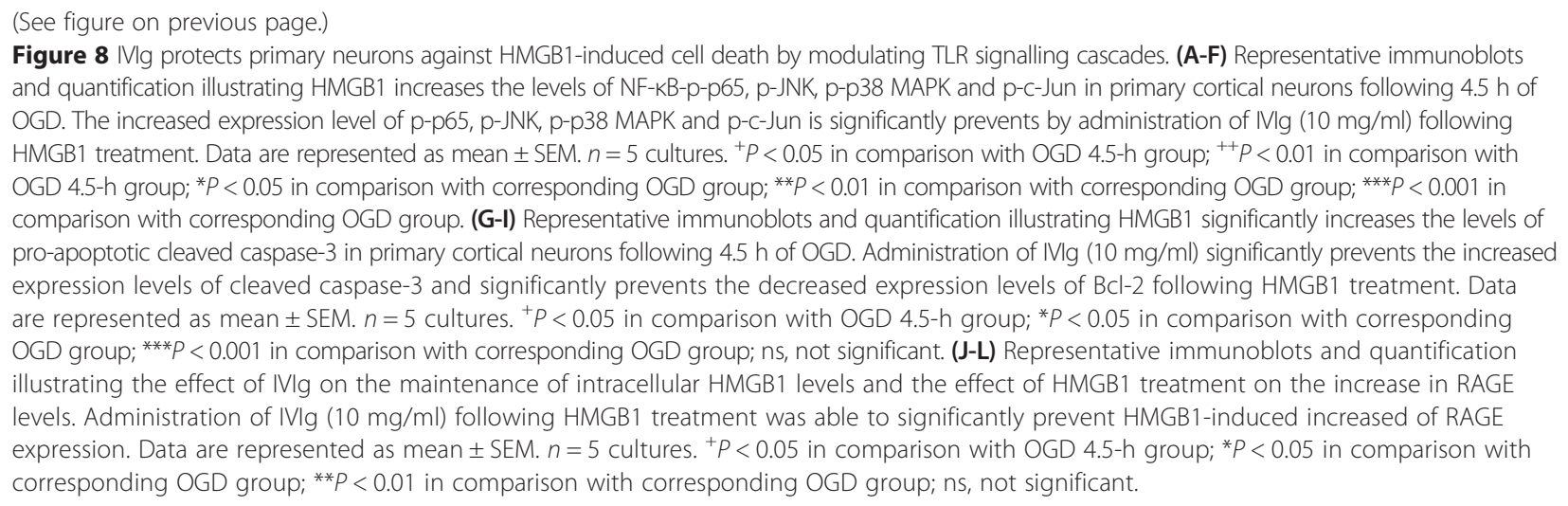

these beneficial effects of IVIg such as attenuating the activity of complement system, the expression of adhesion molecules, the expression and activation of inflammasome pathways and cytokine production [14,25,26]. IVIg acts also by dampening pro-inflammatory and apoptotic gene expressions [15,27]. We and others have previously demonstrated that IVIg treatment reduced brain damage, neurological deficit and mortality in experimental rodent models of stroke $[14,15,28]$. The current study reveals that a reduction in TLR expression and activation partly accounts for the protective effect of IVIg against neuronal cell death following ischemic stroke. The data indicate that IVIg reduces the expression levels of TLR2, TLR4 and TLR8 and dampens downstream signalling cascades associated with TLRs such as the NF- $\mathrm{kB}$ and MAPKs pathways. Furthermore, our data show that IVIg is also targeting HMGB1-mediated TLR signalling in OGD-injured neurons.

Numerous studies have reported pathological roles of TLRs and RAGE in ischemic stroke-induced brain injury $[7,9,23]$. We previously reported that neurons express several TLRs, and that the levels of TLR2, TLR4 and TLR8 are increased in neurons in response to ischemic conditions $[7,9]$. Neurons from both TLR2 knockout and TLR4deficient mice were protected against ischemia, and the amount of brain damage and neurological deficits caused by a stroke were significantly lesser in mice deficient in TLR2 or TLR4 compared with control mice [7]. High concentrations of IVIg prevent neuronal death, but the neuroprotective mechanism is not well established. Recent studies have indicated that IVIg may attenuate the expression and activation of TLR9 in B cells from SLE patients, suggesting a novel additional mechanism of IVIg [1]. Another recent study showed that IVIg and $\mathrm{F}(\mathrm{ab})_{2}$ fragments of IVIg that lacks the Fc region inhibit TLR4mediated activation of dendritic cells [29]. Our data reveals that treatment with IVIg significantly prevented ischemiainduced increased neuronal expressions of TLR2, TLR4 and TLR8. In addition, we have also found that ischemia- induced increased expressions of TLR adaptor and signalling proteins such as MyD88 and TRAF6 were prevented by IVIg treatment. These expression data indicate that IVIg may exert its beneficial effect by modulating the expression and activation of neuronal TLR2, TLR4 and TLR8.

It is well established that the activation of NF- $\mathrm{B}$, JNK and p38 MAPK pathways are implicated in TLR2, TLR4 and TLR8 signalling [2,30]. Our data show that IVIg treatments significantly attenuated the expression level of the phosphorylated forms of NF- $\mathrm{BB}$ p65, JNK, p38 MAPK and c-Jun in neurons following ischemic conditions. It is well known that NF- $\mathrm{kB}$ is a regulator of neuronal apoptosis in cerebral ischemia [31]. Similarly, p38 MAPK, JNK and c-Jun are known to contribute to neuronal cell death following ischemic condition [32]. Our data has shown that IVIg not only prevented ischemia-induced increased expression levels of TLR2, TLR4 and TLR 8 and attenuated its signalling cascades but also ischemia-induced cleavage of apoptotic protease caspase-3.

Our data further suggests that IVIg protects neurons by modulating TLR expression and activation in vitro are also true for in vivo. We have previously reported that IVIg treatment reduces brain damage and improves neurological deficits after cerebral I/R injury [14]. In addition, we have shown that IVIg reduces ischemic stroke-induced infiltration of leukocytes and protects against endothelial dysfunction [27]. We also found evidence that the neuroprotective effects of IVIg are associated with a significant reduction in the levels of NLRP inflammasome proteins as well as precursors of both IL-1 $\beta$ and IL-18 in a mouse model of focal ischemic stroke [26]. Here, we show that the increased expression levels of TLR2, TLR4 and TLR8, adaptor protein MyD88, signalling protein TRAF6, TLR downstream signalling proteins such as NF- $k B$ and MAPKs were significantly prevented in IVIg-treated animals compared to control animals following stroke.

The receptor for advanced glycation endproducts (RAGE) is a member of the immunoglobulin superfamily that is located on the plasma membrane and activated by a variety of 
ligands, including advanced glycation endproducts (AGEs) and HMGB1 [22,23]. Similar to the TLRs, ligand binding to RAGE leads to the activation of several intracellular inflammatory pathways, including NF-kB, JNK and p38 MAPK [33]. We have recently shown that RAGE-deficient mice were protected from ischemic stroke and HMGB1 promotes stroke-induced neuronal cell death by activating signalling cascades associated with RAGE and TLR activation [23]. Experimental evidence suggests that HMGB1 is released in large amounts into the extracellular space immediately after an ischemic brain insult and subsequently induces an inflammatory reaction via the activation of the TLRs and RAGE in affected brain tissues [23]. We have also demonstrated that recombinant soluble RAGE (sRAGE), acting as a decoy receptor for HMGB1, significantly reduced the infiltration of immune cells and improved the outcome of injury in mice subjected to I/R as well as protecting cultured neurons against ischemic cell death [23]. Our current data show that HMGB1 treatment increases TLR2, TLR4 and RAGE expression levels, and IVIg significantly prevented HMGB1-induced increases of these proteins. Similarly, HMGB1-induced MyD88 and TRAF6 expressions were also significantly prevented with IVIg treatment. Furthermore, IVIg significantly prevented HMGB1induced increases of TLR/RAGE signalling cascade proteins such as NF-kB-p-p65, p-JNK, p-p38 MAPK and p-c-Jun.

\section{Conclusions}

Our data establish that IVIg targets expression and activation of TLR and RAGE pathway components as well as protecting neurons against HMGB1-mediated neuronal cell death in ischemic stroke.

\footnotetext{
Abbreviations

AGE: advanced glycation endproducts; ANOVA: one-way analysis of variance; BCl-2: B-cell lymphoma 2; BSA: bovine serum albumin; CCA: common carotid artery; DAMPs: damage-associated molecular patterns; ECA: external carotid artery; GD: glucose deprivation; HMGB1: high-mobility group box 1; I/R: ischemia/reperfusion; ICA: internal carotid artery; IFN: interferon; IKKE: inhibitor of nuclear factor kappa-B kinase subunit epsilon; IVlg: intravenous immunoglobulin; IRAK4: interleukin-1 receptor-associated kinase 4; JNK: c-Jun N-terminal kinase; LPS: lipopolysaccharide; MAPK: mitogen-activated protein kinase; MCA: middle cerebral artery; MyD88: myeloid differentiation primary response gene (88); NF-kB: nuclear factor kappa B; OGD: oxygen and glucose deprivation; PAMPs: pathogenassociated molecular patterns; PRRs: pattern recognition receptors; RAGE: receptor for advanced glycation endproducts; SLE: systemic lupus erythematosus; sRAGE: soluble RAGE; TBK1: TANK-Binding kinase 1; TIR: toll/ interleukin-1 receptor; TLRs: toll-like receptors; TNF: tumour necrosis factor TRAF6: TNF receptor associated factor 6; TRIF: TIR-domain-containing adapter protein inducing IFN- $\beta$..
}

\section{Competing interests}

The authors declare that they have no competing interests.

\section{Authors' contributions}

KZL, MB, SM and TVA conceived the study; TVA and SM coordinated the study; KZL carried out ischemic simulations and protein expression studies; TVA performed MCAO experiments; KZL, SM and TVA wrote the manuscript. All authors read and approved the final manuscript.

\section{Acknowledgements}

The Australian Research Council Future Fellowship to TVA (ARCFT100100427), NUHS Seed Fund for Basic Science Research (R-185-000-255-112) and the start-up fund provided by the National University of Singapore supported this research.

\section{Author details}

${ }^{1}$ Department of Physiology, Yong Loo Lin School of Medicine, National University of Singapore, Block MD9, 2 Medical Drive \#04-01, Singapore 117597, Singapore. ${ }^{2}$ School of Biomedical Sciences, The University of Queensland, Chancellors PI, Brisbane QLD 4072, Australia. ${ }^{3}$ Biovisions, Inc., 9012 Wandering Trail Dr, Potomac, MD, USA. ${ }^{4}$ Australian Institute for Bioengineering and Nanotechnology, The University of Queensland, Building 75, Cnr College Rd \& Cooper Rd, Brisbane, QLD 4072, Australia.

Received: 26 September 2014 Accepted: 2 April 2015

Published online: 15 April 2015

\section{References}

1. Kawai T, Akira S. Signaling to NF-kappaB by toll-like receptors. Trends Mol Med. 2007;13:460-9.

2. Takeda K, Akira S. Toll-like receptors in innate immunity. Int Immunol. 2005;17:1-14.

3. Famakin BM, Mou Y, Ruetzler CA, Bembry J, Maric D, Hallenbeck JM Disruption of downstream MyD88 or TRIF toll-like receptor signaling does not protect against cerebral ischemia. Brain Res. 2011;1388:148-56.

4. Nogueira-Machado JA, Volpe CM, Veloso CA, Chaves MM. HMGB1, TLR and RAGE: a functional tripod that leads to diabetic inflammation. Expert Opin Ther Targets. 2011;15:1023-35.

5. Wang YC, Lin S, Yang QW. Toll-like receptors in cerebral ischemic inflammatory injury. J Neuroinflammation. 2011;8, e134.

6. Ma Y, Li J, Chiu I, Wang Y, Sloane JA, Lü J, et al. Toll-like receptor 8 functions as a negative regulator of neurite outgrowth and inducer of neuronal apoptosis. J Cell Bio. 2006;175:209-15.

7. Tang SC, Arumugam TV, Xu X, Cheng A, Mughal MR, Jo DG, et al. Pivotal role for neuronal toll-like receptors in ischemic brain injury and functional deficits. Proc Natl Acad Sci U S A. 2007;104:13798-803.

8. Lathia JD, Okun E, Tang SC, Griffioen K, Cheng A, Mughal MR, et al. Toll-like receptor 3 is a negative regulator of embryonic neural progenitor cell proliferation. J Neurosci. 2008;28:13978-84

9. Tang SC, Yeh SJ, Li YI, Wang YC, Baik SH, Santro T, et al. Evidence for a detrimental role of TLR8 in ischemic stroke. Exp Neurol. 2013;250:341-7.

10. Arumugam TV, Okun E, Tang SC, Thundyil J, Taylor SM, Woodruff TM. Toll-like receptors in ischemia-reperfusion injury. Shock. 2009:32:4-16.

11. Brea D, Sobrino T, Rodríguez-Yáñez M, Ramos-Cabrer P, Agulla J, Rodríguez-González $\mathrm{R}$, et al. Toll-like receptors 7 and 8 expression is associated with poor outcome and greater inflammatory response in acute ischemic stroke. Clin Immunol. 2011;139:193-8.

12. Lehnardt S, Lehmann S, Kaul D, Tschimmel K, Hoffmann O, Cho S, et al. Toll-like receptor 2 mediates CNS injury in focal cerebral ischemia. J Neuroimmunol. 2007;190:28-33.

13. Tha-In T, Bayry J, Metselaar HJ, Kaveri SV, Kwekkeboom J. Modulation of the cellular immune system by intravenous immunoglobulin. Trends Immunol. 2008;29:608-15.

14. Arumugam TV, Tang SC, Lathia JD, Cheng A, Mughal MR, Chigurupati S, et al. Intravenous immunoglobulin (IVIG) protects the brain against experimental stroke by preventing complement-mediated neuronal cell death. Proc Natl Acad Sci U S A. 2007;104:14104-9.

15. Widiapradja A, Vegh V, Lok KZ, Manzanero S, Thundyil J, Gelderblom M, et al. Intravenous immunoglobulin protects neurons against amyloid betapeptide toxicity and ischemic stroke by attenuating multiple cell death pathways. J Neurochem. 2012;122:321-32.

16. Kessel A, Peri R, Haj R, Snir A, Slobodin G, Sabo E, et al. IVlg attenuates TLR-9 activation in B cells from SLE patients. J Clin Immunol. 2011;31:30-8.

17. Ballow M, Allen C. Intravenous immunoglobulin modulates the maturation of TLR 4-primed peripheral blood monocytes. Clin Immunol. 2011:139:208-14.

18. Murakami K, Suzuki C, Kobayashi D, Nakano A, Fujii A, Sakai A, et al. Intravenous immunoglobulin preparation attenuates LPS-induced production of pro-inflammatory cytokines in human monocytic cells by modulating TLR4-mediated signaling pathways. Naunyn Schmiedebergs Arch Pharmacol. 2012;385:891-8. 
19. Okun E, Arumugam TV, Tang SC, Gleichmann M, Albeck M, Sredni B, et al. The organotellurium compound ammonium trichloro(dioxoethylene-0,0') tellurate enhances neuronal survival and improves functional outcome in an ischemic stroke model in mice. J Neurochem. 2007;102:1232-41.

20. Arumugam TV, Salter JW, Chidlow JH, Ballantyne CM, Kevil CG, Granger DN Contributions of LFA-1 and Mac-1 to brain injury and microvascular dysfunction induced by transient middle cerebral artery occlusion. Am J Physiol Heart Circ Physiol. 2004;287:H2555-60.

21. Okun E, Griffioen KJ, Lathia JD, Tang SC, Mattson MP, Arumugam TV. Toll-like receptors in neurodegeneration. Brain Res Rev. 2009;59:278-92.

22. Ibrahim ZA, Armour CL, Phipps S, Sukkar MB. RAGE and TLRs: relatives, friends or neighbours? Mol Immunol. 2013;56:739-44.

23. Tang SC, Wang TC, Li YI, Lin HC, Manzanero S, Hsieh YH, et al. Functional role of soluble receptor for advanced glycation end products in stroke. Arterioscler Thromb Vasc Biol. 2013;33:585-94.

24. Schwab I, Nimmerjahn F. Intravenous immunoglobulin therapy: how does IgG modulate the immune system? Nat Rev Immunol. 2013;13:176-89.

25. Durandy A, Kaveri SV, Kuijpers TW, Basta M, Miescher S, Ravetch JV, et al. Intravenous immunoglobulin-understanding properties and mechanisms. Clin Exp Immunol. 2009;158 Suppl 1:2-13.

26. Fann DY, Lee SY, Manzanero S, Tang SC, Gelderblom M, Shunduri P, et al. Intravenous immunoglobulin suppresses NLRP1 and NLRP3 inflammasome mediated neuronal death in ischemic stroke. Cell Death Dis. 2013;4, e790.

27. Widiapradja A, Santro T, Basta M, Sobey CG, Manzanero S, Arumugam TV. Intravenous immunoglobulin (IVIg) provides protection against endothelial cell dysfunction and death in ischemic stroke. Exp Transl Stroke Med. 2014;6, e7.

28. Nedelmann M, Ritschel N, Mueller C, Tschernatsch M, Stolz E, Bachmann G, et al. Intravenous immunoglobulin reduced infarct volume but not edema formation in acute stroke. Neuroimmunomodulation. 2010;17:97-102.

29. Bayry J, Bansal K, Kazatchkine MD, Kaveri SV. DC-SIGN and alpha2,6-sialylated IgG Fc interaction is dispensable for the anti-inflammatory activity of IVlg on human dendritic cells. Proc Natl Acad Sci U S A. 2009;106, E24.

30. Li X, Jiang S, Tapping RI. Toll-like receptor signaling in cell proliferation and survival. Cytokine. 2010;49:1-9.

31. Arumugam TV, Cheng YL, Choi YH, Yang S, Yun YK, Park JS, et al. Evidence that gamma-secretase-mediated Notch signaling induces neuronal cell death via the nuclear factor-kappaB-Bcl-2-interacting mediator of cell death pathway in ischemic stroke. Mol Pharmacol. 2011:80:23-32.

32. Bogoyevitch MA, Boehm I, Oakley A, Ketterman AJ, Barr RK. Targeting the JNK MAPK cascade for inhibition: basic science and therapeutic potential. Biochim Biophys Acta. 2004;1697:89-101.

33. Xie J, Méndez JD, Méndez-Valenzuela V, Aguilar-Hernández MM. Cellular signalling of the receptor for advanced gylcation end products (RAGE). Cell Signal. 2013;24:2185-97.

\section{Submit your next manuscript to BioMed Central and take full advantage of:}

- Convenient online submission

- Thorough peer review

- No space constraints or color figure charges

- Immediate publication on acceptance

- Inclusion in PubMed, CAS, Scopus and Google Scholar

- Research which is freely available for redistribution

Submit your manuscript at www.biomedcentral.com/submit 